\title{
Histological and biomechanical analysis of bone and interface reactions around hydroxyapatite-coated intramedullary implants of different stiffness: a pilot study on the goat
}

\author{
Citation for published version (APA): \\ Buma, P., Loon, van, P. J. M., Versleyen, H., Weinans, H., Slooff, T. J. J. H., Groot, de, K., \& Huiskes, H. W. J. \\ (1997). Histological and biomechanical analysis of bone and interface reactions around hydroxyapatite-coated \\ intramedullary implants of different stiffness: a pilot study on the goat. Biomaterials, 18(18), 1251-1260. \\ https://doi.org/10.1016/S0142-9612(97)00064-1
}

DOI:

10.1016/S0142-9612(97)00064-1

Document status and date:

Published: 01/01/1997

\section{Document Version:}

Publisher's PDF, also known as Version of Record (includes final page, issue and volume numbers)

\section{Please check the document version of this publication:}

- A submitted manuscript is the version of the article upon submission and before peer-review. There can be important differences between the submitted version and the official published version of record. People interested in the research are advised to contact the author for the final version of the publication, or visit the DOI to the publisher's website.

- The final author version and the galley proof are versions of the publication after peer review.

- The final published version features the final layout of the paper including the volume, issue and page numbers.

Link to publication

\footnotetext{
General rights

- You may freely distribute the URL identifying the publication in the public portal. follow below link for the End User Agreement:

www.tue.nl/taverne

\section{Take down policy}

If you believe that this document breaches copyright please contact us at:

openaccess@tue.nl

providing details and we will investigate your claim.
}

Copyright and moral rights for the publications made accessible in the public portal are retained by the authors and/or other copyright owners and it is a condition of accessing publications that users recognise and abide by the legal requirements associated with these rights.

- Users may download and print one copy of any publication from the public portal for the purpose of private study or research.

- You may not further distribute the material or use it for any profit-making activity or commercial gain

If the publication is distributed under the terms of Article $25 \mathrm{fa}$ of the Dutch Copyright Act, indicated by the "Taverne" license above, please 


\title{
Histological and biomechanical analysis of bone and interface reactions around hydroxyapatite- coated intramedullary implants of different stiffness: a pilot study on the goat
}

\author{
P. Buma, P.J.M. van Loon, H. Versleyen, H. Weinans, T.J.J.H. Slooff, \\ K. de Groot* and R. Huiskes \\ Iristitute of Orthopaedics, Orthopaedic Research Laboratory, University Hospital Nijmegen, 6500 HB Nijmegen, The \\ Netherlands; "Biomaterials Research Group, Leiden University, School of Medicine, Leiden, The Netherlands
}

\begin{abstract}
We hypothesized that reduced stem stiffness of orthopaedic implants contrlbutes to a high risk of loosening, since interface stresses and relative motions may exceed a tolerable range. To study this hypothesis, throc types of load-bearing implant with different stiffnesscs were inscrted into the tibia of the goat. Histological analysis was performed of bone repair after insertion of the implant, bone ingrowth, interface disruption and loosening. A finite element model of the configuration provided the quantitative range of interface stresses and relative motions for the present experiment. The implants were made out of stainless steel, hollow titanium and a thin titanium core covered with a polyacetal coating. The stiffness ratios of these implants were approximately $10: 4: 1$, respectively. All implants were coated with a layer of hydroxyapatite (HA) in order to minimize the possible biological effects of the different implant materials. Irrespective of the type of implant, there was a repair phase that lasted 6-12 weeks. The stiff implants functioned well. Large areas of bone bonding to the HA layer were found after the repair phase at 12 weeks postoperatively. After 24 weeks, some signs of loosening were observed. More loosening occurred with the hollow titanium and polyacetal implants, mainly during the repair phase. Three hollow titanium and three polyacetal coated implants survived this period, and were killed after 24 weeks. The integrity of the HA layer at the bone-implant interface of the titanium implants was good. In the polyacetal implants, the repair reaction of the cortical bone was ir complete. Bone ingrowth into HA was largely lacking. In conclusion, we found significant differences in the repair and interface reactions around implants of different stiffness. Stiff implants showed favourable initial interface conditions for bone ingrowth. Intermediate and flexible implants provoked unfavourable interface conditions for initial bone ingrowth. The finite element study showed that the flexible stems produce larger micromotions and higher interface stresses at the bone-prosthesis interface than the stiff stems, indicating an explanation for the histological findings. (C) 1997 Elsevier Sicience Limited. All rights reserved
\end{abstract}

Keywords: Total hip arthroplasty, failure mechanism, bone repair, bone remodelling, soft tissue interface, hydroxyapatite

Received 16 December 1996; accepted 21 March 1997

Irrespective of the type of hip prosthesis, cemented or non-cemented, the main reason for revision is aseptic loosening of one of the components ${ }^{1,2}$. Different prosthetic designs have different failure rates ${ }^{3}$. The failure scenario of prosthetic component loosening is complex, since interacting causative biological and mechanical factors are involved. Excessive stresses at the bone-prosthesis interface in cemented and non-

Correspondence to Dr P. Buma. cemented prostheses may play a very important role in the failure mechanism.

Adaptive bone remodelling induced by unnatural stresses in the bone may be detrimental for the survival of prosthetic components ${ }^{4-8}$. To avoid proximal bone atrophy induced by stress shielding, femoral stems were developed that have a relatively high flexibility, matching that of bone (isoelastic prostheses). Indeed, these isoelastic stems showed relatively little proximal calcar resorption, but the failure rates of these types of 
prosthesis are relatively high compared to similarly designed high-modulus stems ${ }^{6,9-11}$. One of the prerequisites for long-term success of prosthetic implants is a stable bone-implant interface ${ }^{12-16}$. Relative motions that surpass $28-40 \mu \mathrm{m}$ will prevent bone ingrowth in porous coated prostheses ${ }^{17,18}$.

It was hypothesized that a stiff stem, provoking relatively small micromotions, has favourable mechanical conditions at the interface for successful bone ingrowth. However, they increase the risk for long-term proximal bone resorption due to stress shielding of the bone. Alternatively, flexible stems will reduce stress shielding, but will generate larger micromotions at the bone-prosthesis interface, and if implanted in a press-fit manner will generate higher interface stresses with the risk of failed bone ingrowth $^{19-21}$. Theoretically, an intermediate prosthetic stiffness could balance stress shielding, interface motion before ingrowth and interface stresses after ingrowth ${ }^{19}$

The events at the bone-prosthesis interface of stems with different stiffness before, during and after the ingrowth process are still poorly understood. The present study was performed in order to describe and understand the processes at the bone-prosthesis interface in detail and to enlarge our knowledge about the failure mechanisms of prosthetic components. More specifically, it was investigated what the tolerable rango of implant stiffness is in order to balance interface relative motion and stress.

Three types of implant with variable stiffness were inserted into the tibia of the goat. The bonding characteristics were analysed histologically at various postoperative periods. Interface stresses and micromotions for the three types of implant were estimated using three-dimensional finite element analysis.

\section{MATERIALS AND METHODS}

Eighteen solid stainless steel, 10 hollow titanium and 10 flexible polyacetal implants with a titanium core were placed in the right tibia of the skeletally adult Dutch milk goat (Capra Hircus Sana). All goats weighed between 45 and $55 \mathrm{~kg}(51.3 \pm 4.3 \mathrm{~kg})$ and were operated upon using standard general andesthesia and disinfection techniques. After a segmental resection of about $15 \mathrm{~mm}$ of the mid-shaft part of the tibia, the distal medullary canal was drilled and reamed with conical intramedullary reamers and cleaned. The implant consisted of two parts: the tapered-shaped distal part was $55 \mathrm{~mm}$ long, with a proximal diameter ranging from 8.7 to $11.2 \mathrm{~mm}$ and a distal diameter $2 \mathrm{~mm}$ smaller. All implants (stainless steel, hollow titanium or polyacetal with a titanium core) were smooth and had a similar surface topography. All implants were fully coated with hydroxyapatite (HA) with a crystallinity of $70 \%$ (CAM implant service BV, Leiden, The Netherlands). The stiffness ratios in bending were 10:4:1, respectively. Before insertion of the implant, the medullary cavity was prepared with tapered rongeurs, ensuring adequate primary press-fit conditions of the implant (as tested manually). After insertion of the implant, rotational stability was ensured by a proximal locking nail. The proximal part of the implant was fixed with bone cement into the proximal tibia and connected to the distal part (Figure 1). Immediately postoperatively, all the goats were radiographed in the anterio-posterior and lateral directions. 'l'hey were first kept in a hammock for 2 days and then allowed full weight-bearing. Postoperative clinical performance and weight-bearing were judged by a rating system ${ }^{22}$ using a scale from 0 (not used at all) to 4 (normal walking and standing). To allow for qualitative evaluations of bone ingrowth and remodelling, all the animals were labelled with three types of fluorochrome $e^{23-25}$, namely oxytetracycline (20 mg per kg per day, for 7 days after the operation), Xylenol Orange $(20 \mathrm{mg}$ per $\mathrm{kg}$ per day, for 4 days in the middle of the postoperative period) and Calcein Green (20 mg per kg per day, for 4 days directly before killing).

Eighteen stainless steel implants were placed, intended for analysis after 3 (three implants), 6 (four implants), 12 (three implants), 24 (four implants) or 48 (four implants) weeks after implantation. Due to loosening, this investigation scheme could not be fully maintained. Ten hollow titanium and 10 polyacetal implants were intended for evaluation after 24 and 48 weeks (five for each time period), but since most fixations failed prematurely in these series, only three could be analysed after 24 weeks for both types of implant. The animals were heparinized and killed by an overdose of sodium pentobarbitone. The hindlegs were perfused via the descending aorta with physiological saline until all blood was removed. The perfusion

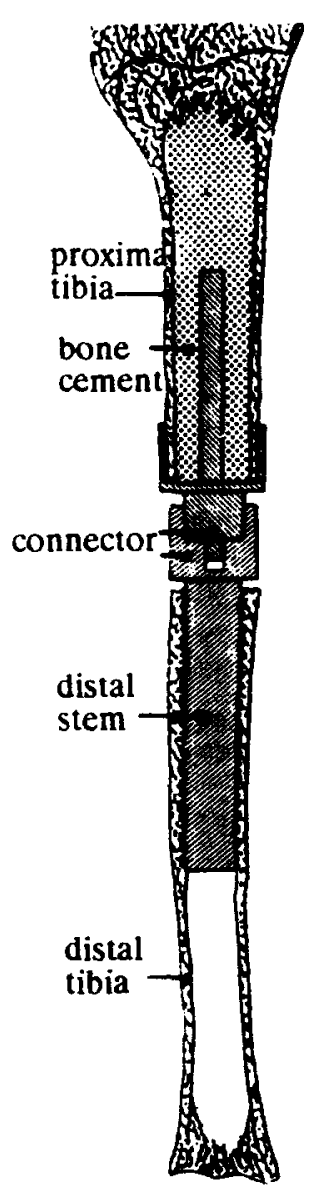

Figure 1 Experimental configuration placed in the tibia of the goat. 
was continued with $4 \%$ paraformaldehyde in a $0.1 \mathrm{M}$ phosphate buffer ( $\mathrm{pH}$ 7.4). Tibias were harvested by careful exarticulation, with an ample musculature cover, leaving the periosteum intact. Fixation was continued for at least 10 days by immersion in the same fixative.

After fixation, tibias were X-rayed and sectioned transversally by means of a water-cooled saw in 3mm-thick slices. The slices were X-rayed again. These slices allowed observations along the entire length of the implant. Three levels were investigated in detail, namely proximally, mid-shaft and distally, i.e. immediately proximal to the tip of the implant. To assess the integrity of the HA layer covering the implant and to evaluate bone ingrowth into the layer of HA, one surface of each slice was polished and studied with incident blue and green light, with or without previous staining ${ }^{26}$. For histology, the slices were decalcified in $25 \%$ ethylene diaminetetraacetate under radiographic control, embedded in poly(methyl methacrylate) (PMMA), thin sectioned (7 $\mu \mathrm{m}$; Jung 2050 microtome) and stained with haematoxylin and eosin (HE). For fluorescence microscopy, 3-mm-thick slices were dehydrated without any pre-embedding staining, embedded in PMMA and sectioned $(30 \mu \mathrm{m})$ with a rotating watercooled diamond saw.

A finite element computer model of the bone inplant configuration was constructed. Computer tomography (CT) scans of a representative tibia were made at serial slices with $2-\mathrm{mm}$ intervals and a finite element (FE) model constructed from the three-dimensional CT data such that the geometry of the FE model represented the scanned tibia accurately ${ }^{19}$. The mechanical properties of the tibial cortex were obtained from experimental mechanical tests. This provided elastic moduli in the longitudinal $\left(E_{l}\right)$, radial $\left(E_{r}\right)$ and circumferential $\left(E_{c}\right)$ directions $\left(E_{\mathrm{l}}=23.2 \mathrm{GPa}, \quad E_{\mathrm{r}}=5.3 \mathrm{GPa} \quad\right.$ and $\left.E_{\mathrm{c}}=10.8 \mathrm{GPa}\right)$. The Poisson ratio was given a value of 0.3 . The external loads acting on the tibia were determined from strain gauge measurements on the tibia of a goat during in vivo experiments whereby several functional gait patterns were recorded ${ }^{27,28}$. A representative loading case from these data was taken and applied to the computer model (Figure 2). The stiffness of the stem was taken in accordance with the stiff stainless steel implant and the flexible polyacetal implant with the titanium core, the two extreme cases in the experiment. The interface conditions wore assumed to be cither fully bonded or debonded with a frictionless interface, again the two extreme situations possible. In this way the range of interface stresses and relative micromotions for the experimentally used implants could be estimated.

\section{RESULTS}

\section{General and clinical observations}

All the goats were arnbulated and allowed full weightbearing after 2 days in a hammock. The clinical score was $2.9( \pm 0.4)$ after 1 week, $3.75( \pm 0.4)$ after 2 weeks and $3.9( \pm 0.3)$ after 3 weeks; this indicates that most

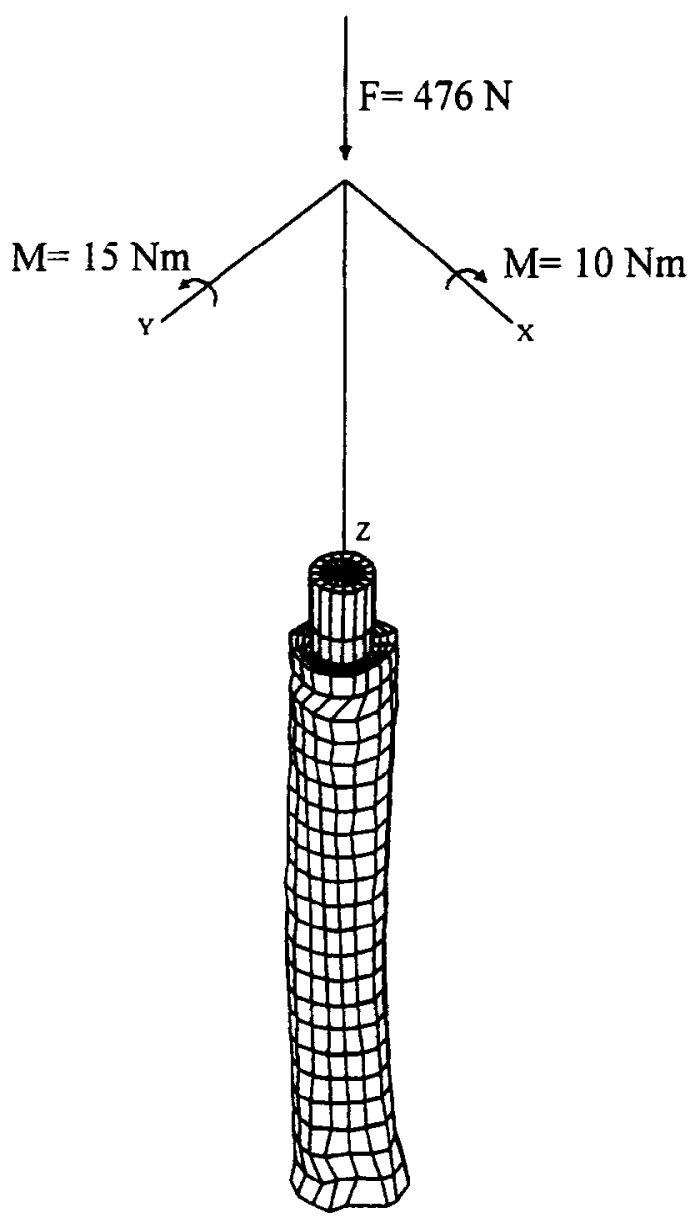

Figure 2 Finite element model of distal portion of the operated tibia. The loads are $476 \mathrm{~N}$ in the z-direction, bending moments of $15 \mathrm{Nm}$ around the $x$-axis and $10 \mathrm{Nm}$ around the $y$-axis, and a torsional moment of $1.5 \mathrm{Nm}$ around the z-axis, where the coordinate system is given relative to a central point at the tibial plateau ${ }^{27}$.

goats achieved normal weight-bearing patterns with normal ranges of motion. No clear differences were found between the different types of implant during this period.

\section{Stainless steel implants}

Two of the 18 implants failed shortly after implantation, due to fractures of the connection between the proximal and distal parts of the implant (one in the 12week group and one in the 48-week group). They were not analysed further. Four other implants showed loosening of the cemented proximal part but could be further analysed, since the distal implant remained well fixed. One case of gross implant loosening occurred after 8 weeks in the 24-week group and two in the 48-week group after 5 and 6 months, respectively. This means that three (out of three) cases at 3 weeks, four (out of four) at 6 weeks, two (out of three) cases at 12 weeks, three (out of four) at 24 weeks and one (out of four) cases at 48 weeks could be analysed.

\section{Hollow titanium implants}

All except three of the 10 implants failed by gross loosening of the distal stem. One failed after 2 weeks and six between 8 and 12 weeks ( $8.5 \pm 3.43$ weeks). The remaining three were analysed after 24 weeks. 


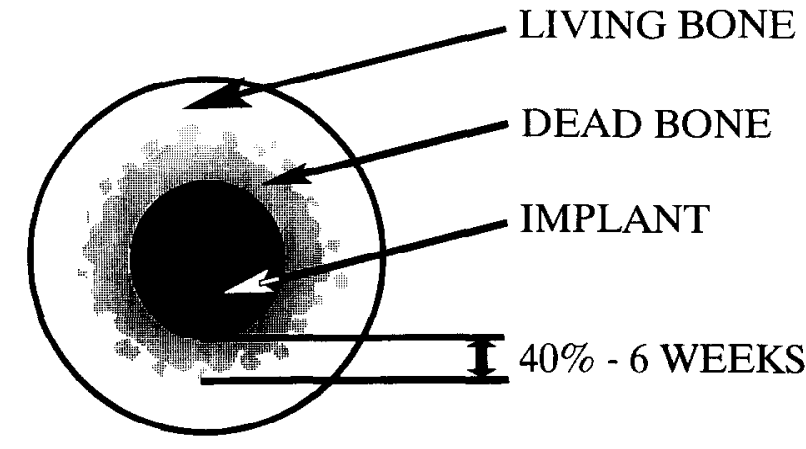

Figure 3 Schematic representation of creeping substitution of endosteal necrotic bone after the operation.

\section{Polyacetal implants}

Three of 10 implants functioned well up to 26 weeks postoperatively. One goat suffered a fracture of the implant connection and was not studied further. Six implants failed duc to gross loosening of the distal implant after $4-7$ weeks ( $5.25 \pm 0.96$ weeks).

\section{Histological observations on postoperative repair}

Directly postoperatively, intimate contact was observed between bone and implant. The spaces between the bones and the implants were between zero and $30 \mu \mathrm{m}$ (Figures $4 A, B, 6 A$ and $7 A-D$ ). This space and some larger gaps, which were observed only occasionally (Figure $4 B$ ), were filled with a loose fibrin clot (Figure $7 C, D, F)$.

After 3 weeks, about one-half of the total surface area at the endosteal side of the cortical bone had become necrotic around the stiff implants (Figures 3 and $4 E$, $G)$. The necrosis, as witnessed by the empty osteocyte lacunae (Figures $4 D$ and $7 C$ ), was circumferential and of variable thickness. As a consequence, the implant was initially always anchored to the bone solely by a press-fit mechanism without osseous integration. A mild postoperative periosteal reaction of woven bone growth was present, particularly at proximal levels, around all the bones (Figure $4 C$ ). Radiographs of the thick sections showed porosity of the cortical bone at the transition from living to necrotic bone (Figures 3 and $4 F, G$ ). Microscopy in these areas showed local areas of revascularization, osteoclastic bone erosion and bone apposition. The temporary porosis in the intermediate region was followed by new bone formation, as shown by the oxytetracycline and/or Calcein Green labelling. This resulted in a mixture of dead necrotic bone and vital remodelled bone, in a process of creeping substitution, moving in the direction of the implant (Figures $3,4 D, F$ and $7 F, G$ ). After viable bone reached the implant, different interface reactions occurred, depending on the type of implant.

\section{Implant-specific observations}

\section{Stainless steel implants}

After 6 weeks, the first local bone ingrowth into the layer of HA was found (Figure $4 \mathrm{H}$ ). Gaps that were present between the implant and the bone had been partly filled by new bone. Local osteoclastic bone lysis of the necrotic bone, directly facing the HA layer, and new bone formation had produced a thin layer of vital bone in direct contact with the HA (Figure 4).
Periosteal bone apposition was generally in regression or had been remodelled into normal Haversian bone. In some cases, osteoclastic bone resorption was found on the periphery, which indicated regression of the periosteal apposition in process.

After 12 weeks, both the $\mathrm{HE}$ and fluorescence sections showed that bone directly facing the HA layer had become completely revascularized. The process of creeping substitution was completed and the implant was surrounded by a layer of newly formed hone. The HA layer was largely intact (Figure $4 K, L)$. Almost complete osseous integration was found between the $\mathrm{HA}$ and the bone. Foci of bone remodelling at the interface, labelled with Calcein Green, had locally impaired the integrity of the HA layer (Figure $5 A, B$ ). In these locations the HA layer had disappeared, probably as an effect of the acid environment produced by the osteoclasts in the process of bone resorption ${ }^{29}$.

The first signs of loosening of the HA layer were observed in all three specimens in the 24-week group, particularly around the distal half of the implant. Between the HA and the metal, an acellular layer of basic fuchsin-stained fibrin-like material was present, or a thin soft tissue interface had formed (Figure $5 C$, $D$ ). Locally, the HA had disintegrated and had been phagocytosed by macrophages (Figure 5D). Metal abrasion particles were seen in the interface as well (Figure 5F). Since this type of implant has a nonarticulating connection, it seems likely that the particles were formed by fretting of the distal part of the implant to the cortical bone.

In the one specimen that was killed after 48 weeks, no radiographic nor functional signs of loosening were detected, but histology showed a pronounced process of interface loosening. Proximally, the cortical bone had become very thin, probably by stress protection of the relatively stiff implant (Figures $4 A$ and $5 E$ ). Distally, the soft tissue interface was thicker between the implant and the bone. HA particles had become engulfed by macrophages. Many dark metal (abrasive) particles were also present (Figure $5 F$ ).

\section{Hollow titanium implants}

The histology of the failed implants was characterized by increased bone turnover at the implantbone interface, bone lysis and soft tissue interface formation (Figure $6 B, C$ ). Only local remnants of the HA coating were found. Goats with wellfunctioning implants were killed and examined after 24 weeks. The interfaces of these implants were characterized by an intact HA layer, without delamination or soft tissue interface formation (Figure 6D, E). Signs of bone remodelling with involvement of the HA layer were scarce. No proximal cortical resorption, as a possible effect of stress shielding, was observed.

\section{Polyacetal implants}

The histology of the interfaces of the three implants that had functioned well for 26 weeks showed characteristic patterns. In the proximal sections, Calcein Green labelling and routine histology showed that the creeping substitution of the necrotic endosteal cortical bone had stopped at a distance from the bone-implant interface, leaving a layer of circumferential necrotic 




Figure 4 A, $X$-ray 27 weeks postoperatively of stainless steel prosthesis in the tibia of the goat. The lower part is the conical shaped HA-coated experimental prosthesis inserted into the conical reamed medullary canal of the tibia; the upper part is cemented to the proximal tibia. Original magnification $\times 1.1$. B, X-ray of thick sections at proximal $(A)$, mid-shaft $(B)$ and distal levels $(C)$ along the prosthesis of the 6-week group. Level $D$ is distal to the tip of the prosthesis. Original magnification $\times 1.1$. C, Periosteal reaction 6 weeks after the operation labelled with oxytetracycline. Original magnification $\times 50$. D, Transition between living and necrotic bone, 6 weeks postoperatively. Note the osteoclastic bone resorption (arrow) and empty osteocyte lacunae. Original magrification $\times 160$. E, Low-magnification photograph (original magnification $\times 10$ ) of an unstained section of tibia 1 week after insertion of the prosthesis, showing the difference in contrast between dark necrotic bone (NB) around the prosthesis and lighter living bone (LB) in the peripheral cortex. The prosthesis is not visible, due to the low level of reflected light. F, Basic fuchsin-stained thin section $(20 \mu \mathrm{m})$ of bone remodelling 6 weeks postoperatively. There are many remodelling cavities (arrows). Original magnification $\times 60$. G, X-ray of $100-\mu$ m-thick section 6 weeks postoperatively, after removal of the prosthetic material. Note the creeping substitution of the cortical bone. Original magnification $\times 4$. $H$, Bone-prosthesis interface after 6 weeks, visualized with incident light. Note that the gap between the bone and HA layer is filled by viable bone. Original magnification $\times 120$. J, Approximately the same location as $H$, but 20 - $\mu \mathrm{m}$-thick section stained with basic fuchsin. Note the complete osseous integration of the cortical bone with the HA layer. Original magnification $\times 80$. K, Interface between the bone and $\mathrm{HA}$ layer 12 weeks after implantation. Note the osseous integration of the HA layer with new bone. Original magnification $\times 50$. L, Enlargement of the encircled area in K. Original magnification $\times 125$. 


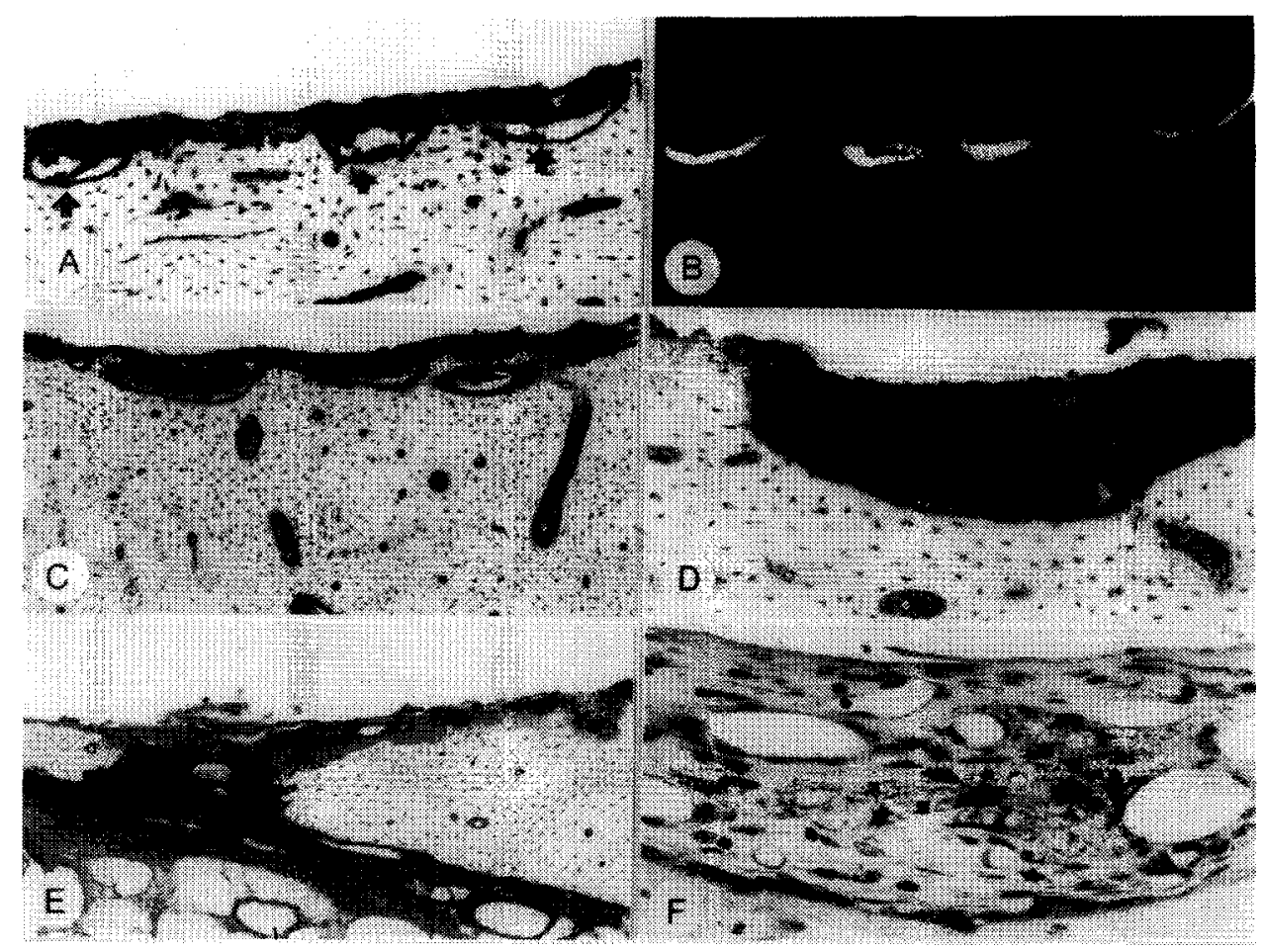

Figure 5 A, Local destruction of the HA layer (arrows) 24 weeks after implantation: active bone remodelling sites. B, Same location as $\mathbf{A}$, but with calcein fluorescence, indicating active bone formation. Original magnification $\times 80$. C, Distal part of the bone around the same prosthesis with local areas of interface formation. Original magnification $\times 40$. D, Same prosthesis, at another location, with many histiocytes loaded with HA particles. $\mathbf{E}$, Cortical bone of a specimen 48 weeks after implantation, at a proximal level. Note the thinning of the cortical bone due to stress shielding (same level as indicated in Figure 1A with white arrow). H, Interface of the same specimen. HE staining showed many histiocytes with abundant dark metal abrasion particles (arrows). Original magnification $\times 220$
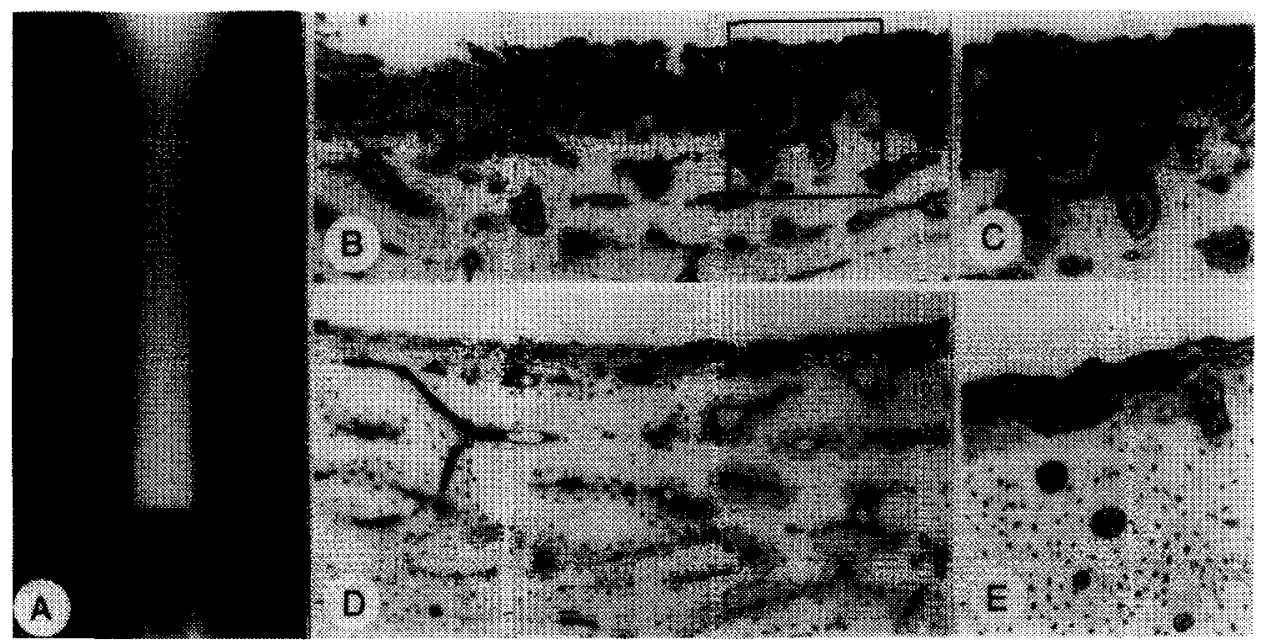

Figure 6 A, X-ray of a hollow titanium prosthesis 24 weeks postoperatively. B, Interface of loose prosthesis 8 weeks postoperatively. Note the dark colour of the fuchsin-stained section, indicating new bone formation, dynamic bone remodelling and total destruction of the HA layer. Original magnification $\times 80$. C, Enlargement of the encircled area in B. Original magnification $\times 160$. D, Interface of a well functioning specimen 24 weeks after implantation. Original magnification $\times 30$. E, Detail of the HA-bone interface. Original magnification $\times 80$.

bone. Osteoblastic and osteoclastic cellular dynamics were lacking and the peri-implant osteocyte lacunae were empty. This resulted in a still considerable necrotic zone around the implant after 24 weeks (Figure $7 C, D, F)$. Locally, fuchsin-stained microfractures were seen, most of them perpendicular to the surface of the endosteal bone (Figure $\left.7 E, F^{\prime}\right)$. The integrity of the HA layer was lost. Instead, a layer of acellular fibrin-like material was present, with many HA particles included (Figure $7 C, D$ ). The proximal bone cortex had thickened compared to the preoperative situation (Figure $7 A$ ). At mid-implant level, more active bone remodelling cavities were found and locally new bone had reached the bone-implant interface. At these locations active bone lysis and interface formation were observed, indicating that the implant was partly surrounded by a fibrous tissue interface and partly by necrotic bone. No microfractures were found at mid-shaft levels. At distal levels around the implant the creeping substitution 


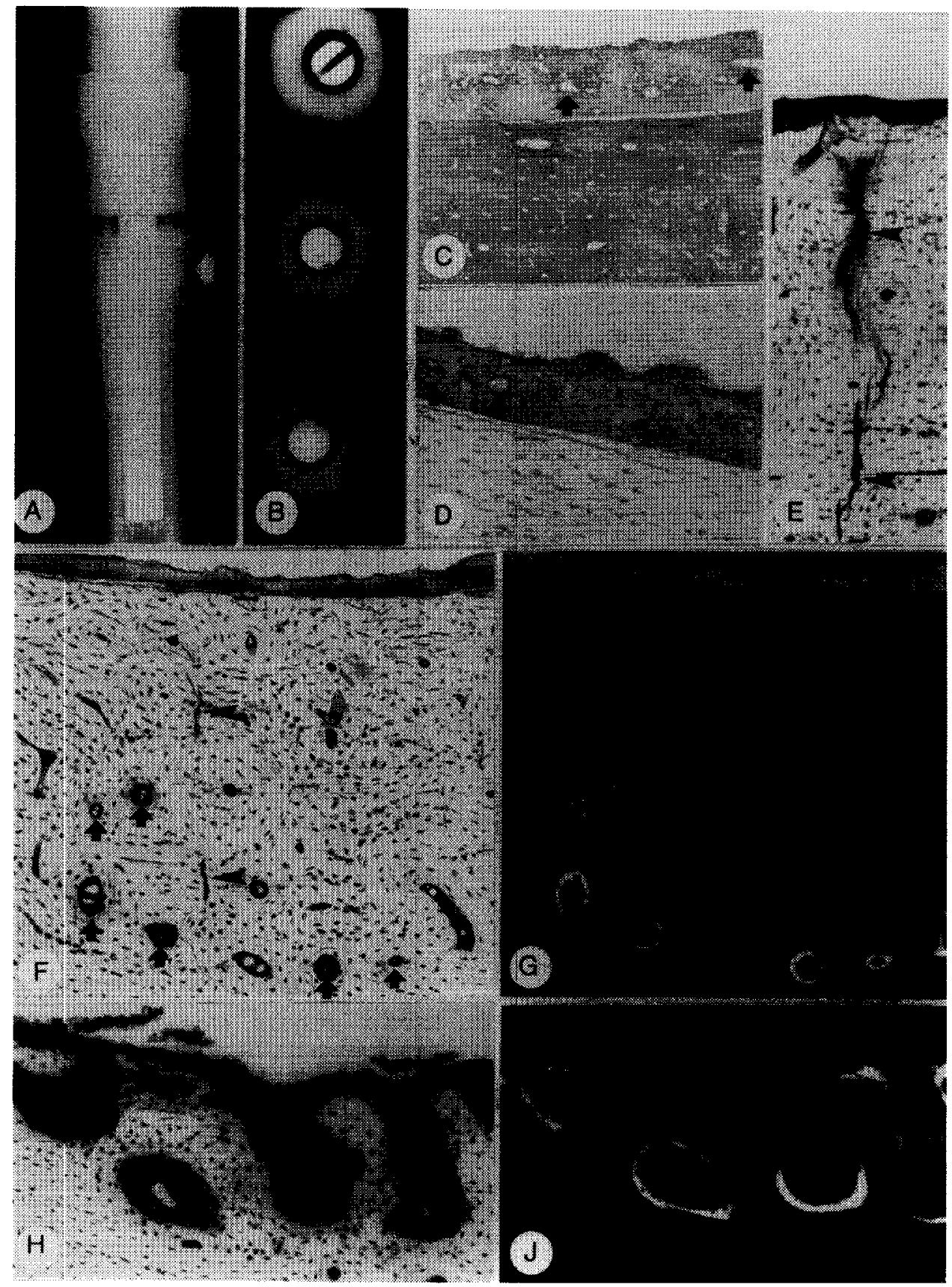

Figure 7 A, Polyacetal HA-coated prosthesis with titanium core. Note the proximal cortical thickening (arrow). Origina magnification $\times 1.1$. B, Cross-sections of the same specimen as A. Original magnification $\times 1.1$. C, D, The interface 24 weeks postoperatively between the prosthesis and bone in non-decalcified (fuchsin stained; D) and decalcified (HE stained; C) sections. Note the many loose HA crystals (arrows) embedded in a fibrin-like material. Original magnification $\times 150$. E, Microfracture in endosteal bone (arrowheads). Original magnification $\times 80$. F, Basic fuchsin-stained proximal thick undecalcified section showing small microfractures (arrowheads). G, Same section, but with incident light for fluorescence detection showing scarce Calcein Green-labelled active remodelling cavities at a distance from the implant-bone interface. Original magnification $\times 80$. H, Fuchsin-stained section showing soft tissue interface at bone-implant interface in distal section. J, Same section with fluorescence of Calcein Green labelling. Note active bone remodelling at bone-prosthesis interface. Original magnification $\times 80$.

had reached the bone-implant interface circumferentially. No bone ingrowth into the disintegrated layer of HA was found, but the implant was surrounded by a fibrous tissue interface (Figure $7 H, \Pi$.

\section{Finite element model analysis}

The FE analysis showed a proximal and distal interface stress peak for the fully bonded stem, which is a typical pattern for such an implant configuration $^{30,31}$. For the flexible implant the proximal stresses were the highest and for the stiff implant the distal stresses were higher (Table 1). Overall, the flexible stem developed higher stresses. For the unbonded analysis the relative motions between stem and bone were evaluated. The flexible stem provoked $4.3 \mathrm{~mm}$ motion at the proximal region versus $3.8 \mathrm{~mm}$ for the stiff stem. 
Table 1 Peak interface stresses around the flexible and stiff stems as calculated in the finite element analysis

\begin{tabular}{lllcrrr}
\hline & $\begin{array}{l}\text { Young's modulus } \\
\text { (GPa) }\end{array}$ & $\begin{array}{l}\text { Proximal } \\
\text { compressive }\end{array}$ & $\begin{array}{l}\text { Proximal } \\
\text { tensional }\end{array}$ & $\begin{array}{l}\text { Proximal } \\
\text { shear }\end{array}$ & $\begin{array}{l}\text { Distal compres- } \\
\text { sive }\end{array}$ & $\begin{array}{l}\text { Distal } \\
\text { tensional }\end{array}$ \\
\hline Flexible stem & 21 & 11.7 & 12.9 & 32.9 & 1.6 & $\begin{array}{l}\text { Distal } \\
\text { shear }\end{array}$ \\
Stiff stem & 210 & 3.2 & 3.4 & 7.7 & 5.0 & 10.7 \\
\hline
\end{tabular}

\section{DISCUSSION}

If one wishes to investigate implant-loosening phenomena, then the experimental model must indeed allow for loosening to occur. In that respect, our model proved quite adequate. Apparently, the forces in the tibia are high in relation to the fixation capacity of the stem, as was also shown in an earlier analysis of implants with a similar model ${ }^{32}$. Hence, the animal model that was developed creates worstcase conditions which are well suited to test implant-loosening scenarios. Moreover, the implant is fixed in cortical bone with a less effective interface revascularization potential compared to trabecular bone, which makes the conditions for ingrowth even worse. On the other hand, however, these differences must be kept in mind when translating the results on osseous integration patterns to the human clinical conditions of a hip replacement, where revascularization occurs rapidly and trabecular fixation is important.

The purpose of this study was to assess the effects of stem stiffness on cortical repair reactions, bone ingrowth, interface disruption and the stem loosening mechanism. The mechanical $\mathrm{FE}$ analyses had shown that the flexible stems produced higher interface motions if unbonded and higher interface stresses if bonded. The specific findings in this study confirmed earlier findings of other stem configurations ${ }^{19-21,30,33}$. As a consequence, one would expect more cases of failed ingrowth and/or late loosening around flexible, as compared to stiff, stems. This was indeed confirmed by the experiments. Although all stems were HA coated in order to standardize the mechanical and biological characteristics of the surface, the bonding strength of this coating to the implants is probably not equal for stainless steel, titanium and polyacetal. It is speculated that, particularly in the latter case, the bonding is weak. Also, due to the flexibility of the polyacetal, disintegration of the $\mathrm{HA}$ layer by mechanical loading, deformation and abrasion of HA particles may have played a role in the process of loosening as compared to the other stem types. Despite the differences with respect to coating fixation, the comparisons between all three types of implants tested in this study point in the same direction, where the general effects of stem stiffness are concerned.

All implants were coated with HA. The effects of HA on new bone formation are well documented. HA coatings accelerate the ingrowth process and thus increase the direct postoperative interface strength of the prosthesis with the bone $^{8,9,12,13,26,29,32,34-44}$. In the present series, this positive effect of HA could not take place directly after the operation, because viable bone could only reach the HA-bone interface after creeping substitu- tion of the nccrotic cortical endostcal bone was completed. Necrosis could have been the result of the heat produced hy the drilling procedure, but since the drills were cooled, it seems more plausible that avascularity due to the trauma is the main factor involved in the generation of the endosteal necrosis. For the stainless steel (rigid) stems, the period that the endosteal bone surface stays fully necrotic appears to be approximately 6 weeks. The stem fixation seems to be secure during this period, but no ingrowth or bonding can take place. The creeping substitution starts from the vascularized periosteal side and slowly moves in the direction of the stem. Generally, this process of creeping substitution progressed at a rate of approximately $120 \mu \mathrm{m}$ per week in the direction of the implant in the case of the stainless steel stems. The first apposition of new bone against the layer of HA was observed after 6 weeks, but due to the varying degree of endosteal necrosis this period also varied and could take as long as 12 weeks. Consequently, the prostheses were only partly anchored to the living bone in this period. For the ingrowth process of the bone to the implant, and hence for the process of osseous integration, this is a very vulnerable period, since the creeping substitution creates quite a porous bone interface and the mechanical press-fitted fixation is endangered. During this ingrowth period, the wellknown positive effects of $\mathrm{HA}$ on implant-bone bonding could be confirmed. Small gaps (if present) were rapidly filled with new bone, resulting in almost $100 \%$ osseous integration of the bone with the HA layer 12 weeks after the operation ${ }^{34,35,37,42,44}$. If this period is survived, another potential loosening mechanism follows for the rigid stem. After 24 weeks, a characteristic failure pattern was found: delamination of the HA-metal bond with fibrous interface formation at the distal implant. This was precisely the location where the highest interface stresses were found in the FE analysis with the bonded interface. It seems likely that the combination of high tension and shear stress (Table 1) provokes debonding of the interface. Once loosening starts, micromotions can occur which can further generate loosening and soft tissue interposition. This fits with the observed osteoclast-mediated dissolution of the HA layer in the remodelling cavities at the HA-bone interface. This led to degradation of the HA layer and reduced the percentage of bonding between the bone and the HA. This process was also observed in human retrieval specimens of HA-coated prostheses ${ }^{29}$. Then, if the HA layer is not replaced by a bony bond, interface stresses in the remaining bonded HA will increase and delamination of the $\mathrm{HA}$ at the implant-HA interface will inevitably occur if a critical level of interface stress is surpassed. Of course, fatigue failure of the HA layer by repetitive loading can also contribute to the loosening process. 
After delamination the implant is again anchored to the bone solely by the press-fit mechanism. Further micromotions during mechanical loading of the implant will induce further soft tissue formation and possibly HA degradation. The end result of this process will be a loose stem in a soft tissue interface. A vicious circle of bone destruction, larger micromotions, subsidence, particle formation and further prosthetic loosening will then be activated, with its well-known characteristics ${ }^{1,15,45-47}$. In this phase of lonsening, fretting of the prosthesis to the cortical bone can induce a metal wear reaction, as observed in the specimens that had been in situ for 24 and 48 weeks. Similar phenomena were observed in a retrieved failed HA-coated hip prosthesis from a patient $^{47}$.

The flexible and jntermediate implants provoked more cases of early loosening as compared to the stiff implants. In the mechanical analyses it was found that the flexible stems generate higher micromotions in the unbounded case and higher interface stresses in the bonded case. Kuiper and Huiskes ${ }^{33}$ reported similar findings for a model of a human femoral stem which included friction and various dynamic loading cases. The relative motions at the interface calculated in the present model seem unrealistically high. The presence of friction between stem and implant will certainly reduce this drastically. From the findings of Kuiper and Huiskes ${ }^{33}$ it was concluded that, in the case with friction included in the analysis, the relative difference in interface motion between a rigid stem and a flexible stem was quite large, up to three-fold at the proximal region. It seems questionable whether the flexible implants grow in at all in the present study. The histological findings from three specimens with the flexible polyacetal implants indicate that there is a different creeping substitution and ingrowth pattern for the flexible implants. Fewer active remodelling cavities were found indicating that the creeping substitution of the necrotic endosteal bone took place irregularly and at a much lower rate. The three flexible implants which survived a period of 24 weeks were still surrounded by large areas of necrotic bone. At the few locations where new bone had reached the fragmented HA layer, no bone ingrowth had occurred. Instead, bone erosions were found at these locations. The reason for this altered pattern of creeping substitution is unclear, but based on the present findings we hypothesize that the stresses in the bone play an important role in the development of the creeping substitution process.

\section{CONCLUSIONS}

The present results give evidence that the stiffness of the prosthetic material is a very important factor for the success of an intramedullary stem. Rapid osseous integration of the prosthesis with the bone was achieved with a stiff stem. Intermediate stiffness was found to be a favourable condition for long-term lasting bonding between the HA layer on the stem and the bone, but there was a considerable risk of failure during the ingrowth period, in particular during the period that creeping substitution had reached the implant surface. In the stainless steel group the creeping substitutions generally progressed at a speed of $120 \mu \mathrm{m}$ per week. In the flexible stem group the creeping substitution progressed much slower. The bone stresses and the relative displacements at the interface between the flexible stems and the bone were probably too large for proper bone ingrowth into the layer of $\mathrm{HA}$, and as a consequence most flexible implants failed.

\section{REFERENCES}

1. Goldring, S.R., Schiller, A. L., Roulke, M., Roelrke, C. M., O'Neill, D. A. and Harris, W.H., The synoviallike membrane at the bone-cement interface in loose total hip replacements and its proposed role in bone lysis. J. Bone Joint Surg., 1983, 65A, 575-583.

2. Maloney, W. J., Jasty, M., Harris, W. H., Galante, J. O., Callaghan, J.J., Endosteal erosion in association with stable uncemented femoral components. J. Bone Joint Surg., 1990, 72A, 1025-1034.

3. Ahnfelt, L., Herberts, P., Malchau, H. and Andersson, G. B., Prognosis of total hip replacement. $\Lambda$ Swedish multicenter study of 4,664 revisions. Acta Orthop. Scand. (Suppl.), 1990, 238, 1-26.

4. Bobyn, J. D., Mortimer, E.S., Glassman, A.H., Engh, C. A., Miller, J.E. and Brooks, C.E., Producing and avoiding stress shielding. Clin. Orthop., 1992, 274, 7996.

5. Engh. C. A. and Bobyn. J.D., The influence of stem size and extent of porous coating on femoral bone resorption after primary cementless hip arthroplasty. Clin. Orthop. Rel. Res., 1988, 231, 7-28.

6. Huiskes, R., Weinans, H. and Dalstra, M., Adaptive bone remodeling and hiomechanical design considerations for noncemented total hip arthroplasty. Orthopedics, 1989, 12, 1255-1267.

7. Kosenberg, A., Cementless total hip arthroplasty: femoral remodeling and clinical experience. Orthopedics, 1989, 12, 1223-1233.

8. Turner, T. M., Summer, D. R., Urban, R. M., Rivero, D.P. and Galante, J.O., A comparative study of porous coatings in a weight-bearing total hip-arthroplasty model. J. Bone Joint Surg. 1986, 68A, 1396-1409.

9. Sarmiento, A. and Gruen, T. A., Radiographic analysis of low-modulus titanium-alloy femoral total hip component. J. Bone Joint Surg., 1985, 67A, 48-56.

10. Niinimäki, T., Puranen, J. and Jalovaara, P., Total hip arthroplasty using isoelastic femoral stems. A seven- to nine-year follow-up in 108 patients. J. Bone Joint Surg., 1994, 76B, 413-418.

11. Sarmiento, A., Natarajan, V., Gruen, T.A. and McMahon, M., Radiographic performance of two different total hip cemented arthroplasties. A survivorship analysis. Orthop. Clin. North Am., 1988, 19, 505-516.

12. Hainau, B., Reimann, I., Dorph, S., Rechnagel, K., Henschel, A. and Kragh, F., Porous-coated knee arthroplasty. A case report concerning bone ingrowth. Clin. Orthop., 1989, 239, 178-184.

13. Hansson, H. A., Albrektsson, T. and Branemark, P. I., Structural aspects of the interface between tissue and titanium implants. J. Prosthet. Dent, 1983, 50, 108-113.

14. Jasty, M. and Harris, W.H., Observations on factors controlling bony ingrowth into weight-bearing, porous canine hip replacements. In Non-cemented Total Hip Arthroplasty, ed. R. Fitzgerald. Raven Press, New York, 1988 , p. 175.

15. Kozinn, S. C., Johanson, N. A. and Bullough, P.G., The biologic interface between bone and cementless femoral endoprostheses. J. Arthroplasty, 1986, 1, 249259 . 
16. Söballe, K., Hydroxyapatite ceramic coating for bone implant fixation. Mechanical and histological studies in dogs. Acta Orthop. Scand., 1993, 64 (Suppl. 255), 158.

17. Burke, D. W., O'Connor, D. O., Zalenski, E. B., Jasty, M. and Harris, W.H., Micromotion of cemented and uncemented femoral components. J. Bone Joint Surg. 1991, 73B, 33-37.

18. Pilliar, R. M., Lee, J. M. and Maniatopoulos, C., Observations on the effect of movement on bone ingrowth into porous-surfaced implants. Clin. Orthop., 1986, 208, 108-113.

19. Huiskes, R., Weinans, H. and Rietbergen, B. van, The relationship between stress shielding and bone resorption around total hip stems and the effects of flexible materials. Clin. Orthop., 1992, 274, 124-134.

20. Weinans, H., Huiskes, R. and Grootenboer, H. J., Effects of material properties of femoral hip components on bone remodeling. J. Orthop. Res., 1992, 10, 845-853.

21. Weinans, H., Huiskes, R. and Grootenboer, H. J., Effects of fit and bonding characteristics of femoral stems on adaptive bone remodeling. J. Binmech. Eng., 1994, 116, 393-400.

22. Ypma, J.F.A.M., Strength and ingrowth aspects of porous acrylic bone cement. Thesis, University of Nijmegen, 1981.

23. Benske, J., Schunke, M. and Tillmann, B., Subchondral bone formation in arthrosis. Polychrome labeling studies in mice. Acta Orthop. Scand., 1988, 59, 536541.

24. Frost, H. M., Tetracycline-based histological analysis of bone remodeling. Calcif. Tiss. Res., 1969, 3, 211-337.

25. Rhan, B. A. and Perren, S. M., Xylenol orange, a fluorochrome useful in polychrome sequential labeling of calcifying tissues. Stain Technol., 1971, 46, 125-129.

26. Buma, P., Versleyen, H. and Slooff, T.J.J.H., A procedure for the visualization of bone with hydroxylapatite-coated implants. Clin. Mater., 1994, 15, 93-99.

27. Roszek, B., Weinans, H., Loon, P. van and Huiskes, R., In vivo measurements of the loading conditions on the tibia of the goat. Acta Anat., Basel, 1993, 146, 188-192.

28. Weinans, H. and Blankevoort, L., Reconstruction of bone loading conditions from in vivo strain measurements. I. Biomesh., 1995, 28, 739-744.

29. Bauer, T.W., Geesink, R.G.T., Zimmerman, R. and McMahon, J.T., Hydroxyapatite-coated femoral stems. Histological analysis of components retrieved at autopsy. J. Bone Joint Surg., 1991, 73A, 1439-1452.

30. Huiskes, R., Weinans, H., Grootenboer, H. J., Dalstra, M. Fudala, B. and Slooff, T. J., Adaptive bone-remodeling theory applied to prosthetic-design analysis. J. Biomech., 1987, 20, 1135-1150.

31. Huiskes, R., Stress patterns, failure modes, and bone remodeling. In Non-cementcd Total Hip Arthroplasty, ed. R. Fitzgerald. Raven Press, New York, 1988, pp. 283-302.

32. Loon, P. J. M. van, Weinans, H., Huiskes, R., Groot, K. de and Slooff, T.J.J.H., Intramedullary fixation with screwed, conical stems-unsolicited results from animal experiments. Clin. Mater, 1992, 10, 239-242.
33. Kuiper, J.H. and Huiskes, R., Friction and stem stiffness affect dynamic interface motion in total hip replacement. J. Orthop. Res., 1996, 14, 36-43.

34. Cook, S. D., Thomas, K. A., Kay, J. F. and Jarcho, M. J. Hydroxyapatite-coated titanium for orthopedic implant applications. Clin. Orthop., 1986, 232, 225-243.

35. DeLange, G. L. and Donath, K., Interface between bone tissue and implants of solid hydroxyapatite or hydroxyapatite-coated titanium implants. Biomaterials, $1989,10,121-125$.

36. Geesink, R. G., Groot, K. de and Klein, C. P., Chemical implant fixation using hydroxylapatite coatings. The development of a human total hip prosthesis for chemical fixation of the bone using hydroxylapatite coating on titanium substrates. Clin. Orthop., 1987, 225, 147-170.

37. Geesink, R.G. T., Groot, K. de and Klein, C.P. A. T. Bonding of bone to apatite-coated implants. J. Bone Joint Surg., 1988, 70B, 17-22.

38. Kitsugi, T., Yamamuro, T., Takeuchi, H. and Ono, M. Bonding behaviour of three types of hydroxyapatite with different sintering temperatures implanted in bone. Clin. Orthop., 1988, 234, 280-290.

39. Oonishi, H., Yamamoto, M., Ishimaru, H. et al., The effect of hydroxyapatite coating on bone growth into porous titanium alloy implants. J. Bone Joint Surg., 1989, 71B, 213-216.

40. Söballe, K., Hansen, E.S., Brockstedt-Rasmussen, H., Pedersen, C. M. and Bunger, C., Bone graft incorporation around titanium-alloy- and hydroxyapatite-coated implants in dogs. Clin. Orthop., 1992, 274, 282-293.

41. Söballe, K., Brockstedt-Rasmussen, II., Ilansen, E. S. and Bunger, C., Hydroxyapatite coating modifies implant membrane formation. Controlled micromotion studied in dogs. Acta Orthop. Scand., 1992, 63, 128140

42. Stephenson, P.K., Freeman, M. A., Revell, P. A., Germain, J., Tuke, M. and Pirie, C.J., The effect of hydroxyapatite coating on ingrowth of bone into cavities in an implant. J. Arthroplasty, 1991, 6, 51-58.

43. Thomas, K. A., Cook, S. D., Haddad, R. J., Kay, J. F. and Jarcho, M., Biologic response to hydroxylapatite-coated titanium hips. A preliminary study in dogs. J. Arthroplasty, 1989, 4, 43-53.

44. Jarcho, M., Calcium phosphate ceramics and hard tissue prosthetics. Clin. Orthop., 1981, 157, 259-278.

45. Goodman, S. B., Chin, R.C., Chiou, S. S., Schurman, D. J., Woolson, S.T. and Masada, M.P., A clinicalpathologic-biochemical study of the membrane surrounding loosened and nonloosened total hip arthroplasties. Clin. Orthop., 1989, 244, 182-187.

46. Willert, H. G., Ludwig, J. and Semlitsch, M., Reaction of bone to methacrylate after hip arthroplasty: a long-term gross, light microscopic, and scanning electron microscopic study. J. Bone Joint Surg., 1974, 56A, 1368-1382.

47. Buma, P. and Gardeniers, J.W., Tissue reactions around a hydroxyapatite-coated hip prosthesis. Case report of a retrieved specimen. J. Arthroplasty, 1995, 10, 389-395. 